\title{
Early postnatal cranial vault reduction and fixation surgery for severe hydrocephalic macrocephaly
}

\author{
Rajiv R. Iyer, MD, ${ }^{1}$ Carolyn M. Carey, MD, ${ }^{1,2}$ S. Alex Rottgers, MD, ${ }^{3}$ Lisa Tetreault, RN, BSN, CCRP, ${ }^{4}$ \\ Nir Shimony, MD, ${ }^{1}$ Jennifer Katzenstein, PhD, ${ }^{1}$ Ernesto Ruas, MD, ${ }^{3}$ and Gerald F. Tuite, MD ${ }^{1,2}$

\begin{abstract}
${ }^{1}$ Institute for Neuroscience and Brain Protection, ${ }^{3}$ Division of Plastic Surgery, ${ }^{4}$ Department of Clinical and Translational Research, Johns Hopkins All Children's Hospital, St. Petersburg; and 2Department of Neurosurgery and Brain Repair, Morsani College of
\end{abstract} \\ Medicine, University of South Florida, Tampa, Florida
}

\begin{abstract}
OBJECTIVE Infants with severe hydrocephalus and extreme macrocephaly typically undergo CSF diversion early in life, which can result in significant cranial deformity due to CSF overdrainage. In this scenario, overlap of the cranial plates can precede the development of secondary synostosis and/or severe, permanent cranial deformity. As a result, extensive cranial vault remodeling is sometimes undertaken later in life, which is often challenging and has been associated with mortality and a high morbidity rate. The authors have previously described a technique for early postnatal cranial vault reduction and fixation (CVRF), in which the calvarial bones are stabilized using absorbable fixation plates in the neonatal period, in an attempt to facilitate patient positioning, simplify hydrocephalus management, and improve cosmesis. Here, the authors describe their institutional experience managing patients with extreme neonatal hydrocephalus with CSF diversion, with and without CVRF, over the past 12 years.
\end{abstract}

METHODS The authors retrospectively reviewed the charts of infants with extreme hydrocephalus (head circumference $>49 \mathrm{~cm}$ ) treated at their children's hospital with ventriculoperitoneal shunting, with or without CVRF, between 2005 and 2017. Data collected included age, sex, etiology of hydrocephalus, type of CVRF performed (anterior, posterior, or combined), follow-up duration, orbitofrontal circumference, craniometric measurements, intraoperative blood loss, operative duration, and postoperative complications. Developmental data were collected using the third edition of the Ages and Stages Questionnaire. Photographic imaging was used to demonstrate esthetic outcomes, and family questionnaires were used to evaluate satisfaction with the esthetic outcome.

RESULTS Eleven patients with extreme neonatal hydrocephalus underwent CSF shunting; 5 underwent shunting alone and 6 patients underwent shunting and CVRF. For patients who underwent shunting and CVRF, the median age at CVRF was 6 days and the median interval between shunt placement and CVRF was 2.5 days. The mean extent of calvarial vault volume reduction was $44.5 \%( \pm 3.9 \%)$. The mean duration of the CVRF procedure was 108 minutes, and 5 of 6 patients required intraoperative transfusion. Of the 5 patients who underwent shunting alone, 3 developed severe cranial deformities. Of 6 patients who underwent shunting and CVRF, 1 had a poor cosmetic outcome. In the shunting-alone group, 2 patients died and 1 required extensive cranial vault correction at 10 years of age. One patient in the shunting and CVRF group also died.

CONCLUSIONS CVRF in combination with CSF shunting in the neonatal period can simplify the treatment of the rare case of severe hydrocephalic macrocephaly and leads to cosmetic outcomes that are considered good by their families. https://thejns.org/doi/abs/10.3171/2017.11.PEDS17173

KEY WORDS hydrocephalus; CSF shunt; cranial reduction; cranial vault reconstruction; craniosynostosis; deformity; cranioplasty; surgical technique

$\mathrm{W}$ HILE rare, severe hydrocephalic macrocephaly can cause significant morbidity in infants due to positioning difficulties, skin breakdown, and poor cosmesis. ${ }^{2,14}$ These challenges pose a significant burden on patients, families, and care providers. In an effort to combat these issues, several groups over the past decades have described a variety of surgical techniques performed with the common goal of reducing calvarial volumes, referred to as "reduction cranioplasty" or "cranial vault reduction" (CVR)., ${ }^{4,10,14,17}$ These interventions have com-

ABBREVIATIONS $A S Q=$ Ages and Stages Questionnaire; $C V R=$ cranial vault reduction; $C V R F=$ cranial vault reduction and fixation; $O D D=$ oblique diagonal difference; ODDi = ODD index; VPS = ventriculoperitoneal shunt.

SUBMITTED April 4, 2017. ACCEPTED November 9, 2017.

INCLUDE WHEN CITING Published online March 2, 2018; DOI: 10.3171/2017.11.PEDS17173. 
monly been performed in the developing years of childhood and adolescence. Such operations, performed in either single or multiple stages with multidisciplinary craniofacial teams, are extensive. Potential surgical morbidities include infection, blood loss, sagittal sinus injury, and large CSF shifts with resultant intracranial hemorrhage. A mortality rate of approximately $4 \%$ has been demonstrated in the relatively small number of cases previously reported in the literature., ${ }^{9,19}$

Despite the use of programmable ventriculoperitoneal shunt (VPS) valves, antisiphon devices, and frequent repositioning, overdrainage and associated cranial dysmorphism still occur in the treatment of severe hydrocephalus. We have previously described a novel approach to cranial reduction in a neonate with severe hydrocephalic macrocephaly, in whom the mobile and overlapping cranial bones that develop after shunt placement are stabilized by connecting adjacent cranial bones with a resorbable plate placed in the epidural space. ${ }^{8}$ Here, we report our institutional experience with the management of cases of extreme neonatal hydrocephalus using CSF diversion, with and without cranial vault reduction and fixation (CVRF), over the 12-year period.

\section{Methods}

\section{Patient Selection/Data Collection}

We retrospectively reviewed the charts of neonates with extreme hydrocephalic macrocephaly (head circumference $>49 \mathrm{~cm}$ ) treated at our children's hospital with VPS placement, with or without CVRF, between 2005 and 2017. We restricted the use of the CVRF technique to patients whose heads were severely disproportionate to their body size and who developed significantly overlapping sutures and cranial deformity following CSF shunting, despite the use of programmable shunt valves.

Surviving patients returned for imaging, professional photography of their head shape, completion of family outcomes questionnaires to assess developmental progress and perceptions of esthetic outcome, and standard head anthropometric measurements. Patient demographics, head growth charts, clinical images, and operative reports were collected and reviewed. Calvarial volumes before and immediately after CVRF were calculated using volumetric software based on CT or MRI studies (BrainLab).

Craniometric measurements were performed manually and confirmed with craniometric software (SmartSoc 3D Capturing System, Orthomerica Products Inc.). Measurements included head circumference, cranial index (mediolateral width/anteroposterior length), cranial diagonals, oblique diagonal difference (ODD; difference between cranial diagonals), and the ODD index (ODDi; ratio between the longer and shorter cranial diagonals). ${ }^{16}$ Esthetic outcome questionnaires were given to families and practitioners on the research team.

In addition, the Ages and Stages Questionnaire, Third Edition (ASQ-3), was administered., ${ }^{3,15}$ This age-based questionnaire is completed by parents and evaluates developmental progress in 5 domains (communication, gross motor function, fine motor function, problem solving, and personal-social). Scoring is based on where a child falls relative to established cutoff scores: above the cutoff (normal development), close to cutoff/at-risk (1-2 standard deviations below the mean, "near"), and below cutoff.

This study was conducted in accordance with the Johns Hopkins All Children's Hospital institutional review board protocol.

\section{Surgical Technique}

A description of our technique has been previously published (Fig. 1) ${ }^{8}$ In brief, patients with extreme forms of macrocephalic shunted hydrocephalus undergo surgery to approximate and fixate the widely separated cranial sutures. The primary goals of each CVRF operation are to reduce the volume of the cranial vault so as to better appose the calvarial bones and create a rounder, less dysmorphic head shape and to stabilize the intracranial volume so as to simplify management of CSF flow dynamics and minimize the need for VPS reprogramming and/or revision.

The goal in an anterior CVRF is apposition of the frontal and parietal bones. In a posterior CVRF, union of the parietal and occipital bones is the desired result. For anterior, posterior, or combined anterior-posterior CVRF, a bicoronal incision is fashioned such that access to the required regions of the skull is feasible. If the VPS is exposed, it is covered with an antibiotic-soaked sponge and manipulated to a minimal extent during the procedure. Anterior corrections alone are performed with the patient lying supine, while posterior-alone and combined anterior-posterior corrections are performed with the patient in a modified sphinx position. After bony exposure, a shunt tap is performed to slowly aspirate enough CSF to allow for cranial bone approximation. Calvarial bone alignment and fixation is then performed using epidural bioresorbable plates contoured with heat, which are held in place using sutures through the bone and plate (Fig. 2). In some cases, osteotomies are performed to enhance the shape of the calvaria. Dural plication sutures are not used, and care is taken during the reconstruction to avoid sagittal sinus constriction.

\section{Results \\ Patient Characteristics}

A total of 11 patients with extreme forms of hydrocephalus underwent VPS placement during the time period. Five patients underwent VPS insertion alone, and 6 patients underwent VPS placement + CVRF (Table 1). The median age at VPS placement was 3.5 days ( \pm 4.9 days) and the mean age at CVRF was 6 days (range 1-45 days). Mean preshunting head circumference was $51.9 \mathrm{~cm}( \pm 3.7$ $\mathrm{cm}$ ), with all patients falling above the 99th percentile. Etiologies of hydrocephalus included holoprosencephaly $(\mathrm{n}=$ 4), aqueductal stenosis $(n=5)$, and Dandy-Walker malformation $(n=2)$.

\section{VPS Placement + CVRF Outcomes}

Extended clinical follow-up for the VPS placement + CVRF group was available for 5 of 6 patients with a median follow-up of 43 months (range 10-60 months). 

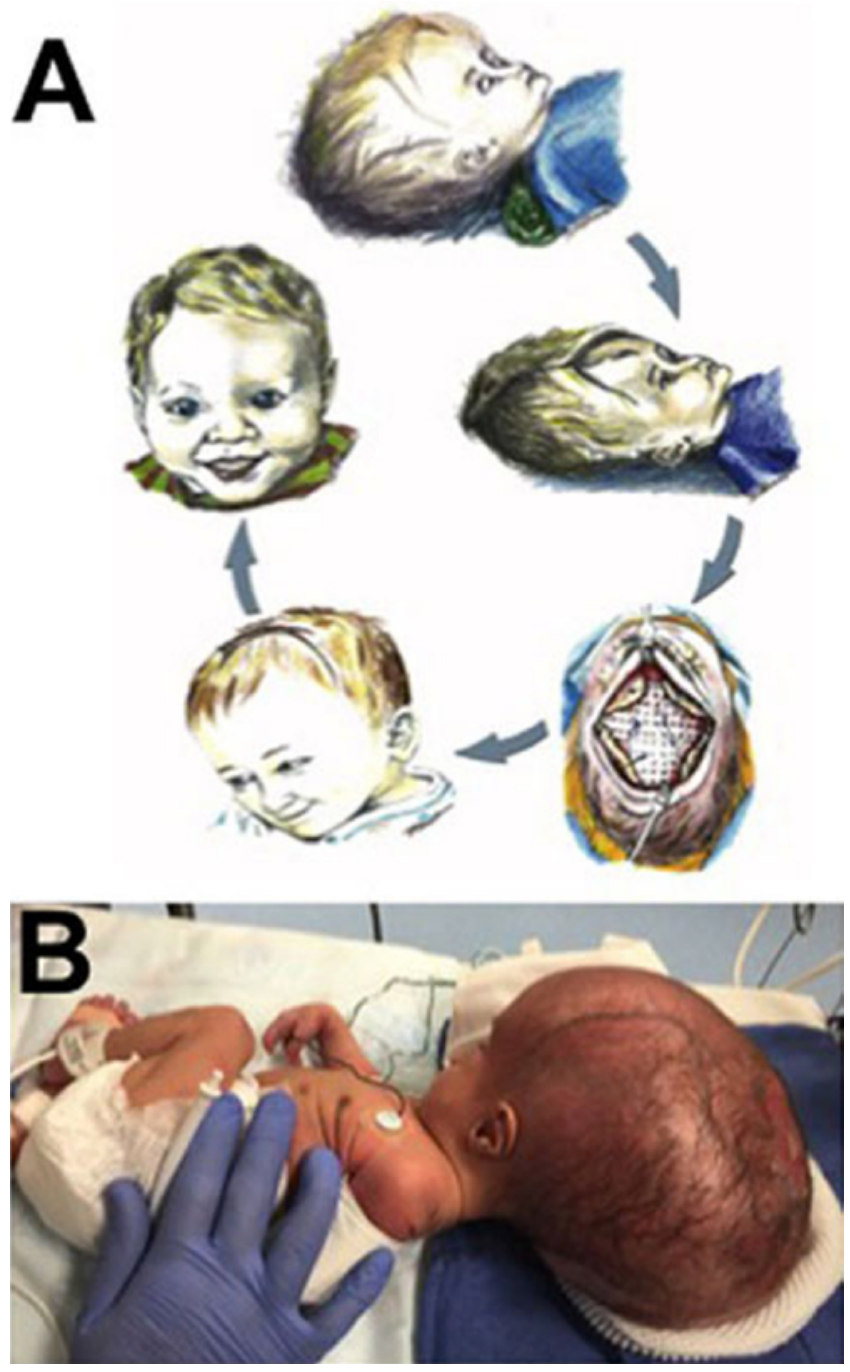

FIG. 1. CVRF for extreme macrocephaly related to severe hydrocephalus. A: Artist's illustration of previously described CVRF procedure, demonstrating extreme macrocephaly (uppermost) and, in clockwise order, postshunting cranial disfigurement, an intraoperative view of the CVRF surgery, early postoperative appearance, and delayed postoperative appearance with a good cosmetic outcome. Originally published in Manwaring et al: J Neurosurg Pediatr 11:210-213, 2013. ${ }^{8}$ B: Example of a neonate with extreme macrocephaly associated with severe hydrocephalus (patient 6). Figure is available in color online only.

In all patients in the VPS placement + CVRF group, a programmable shunt was implanted. The shunt placement and the CVRF were separate procedures in 5 of the 6 patients. A single surgery for shunt placement and CVRF was performed in 1 patient because the cranial deformity was very severe in the operating room immediately after shunting. Single-stage CVRF was performed in 5 out of 6 patients. A second CVRF procedure during a separate operation was required in 1 patient (patient 3), who had a persistently posterior oxycephalic head shape approximately 1 year following the initial CVRF. An anterior correction was performed in 4 patients, and a combined anterior-posterior correction was performed in 2 patients. The mean operative duration was 108 minutes. Estimated
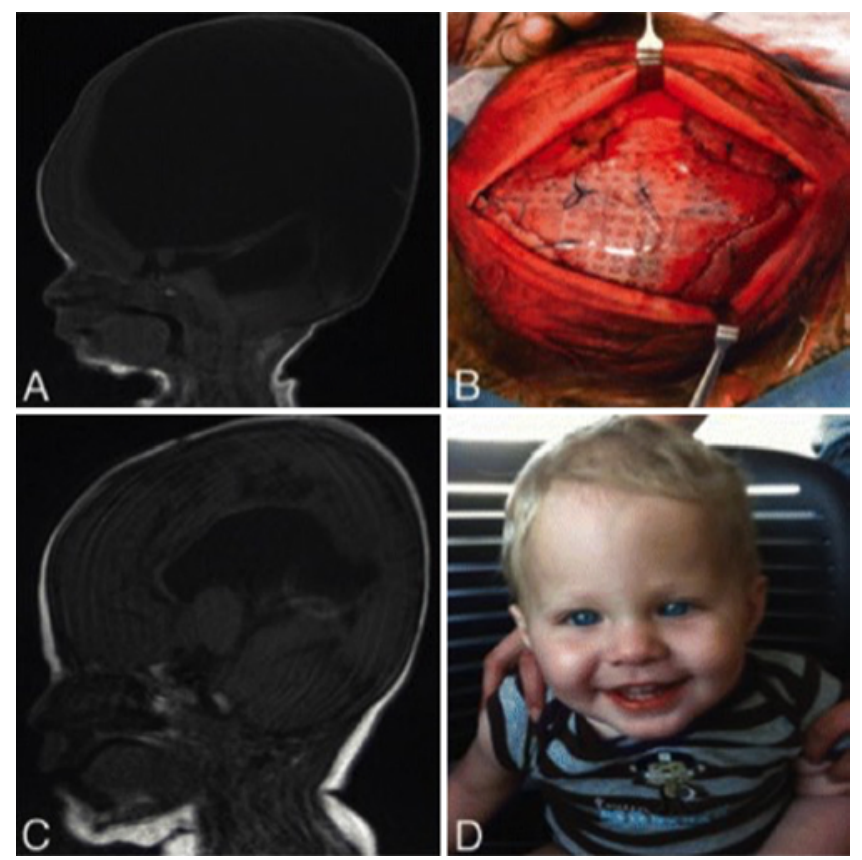

D

FIG. 2. CVRF technique. A and C: Sagittal T1-weighted MR images demonstrating severe preoperative hydrocephalus and a large cranial vault size $(A)$ and postoperative reduction in ventricular caliber and more normal face-to-calvaria proportion (C). B: Intraoperative vertex view of the CVRF procedure using a bioresorbable epidural plate at the anterior fontanel. D: Frontal photograph at 14 months following CVRF demonstrating a good cosmetic outcome. Originally published in Manwaring et al: J Neurosurg Pediatr 11:210-213, 2013. ${ }^{8}$ Figure is available in color online only.

blood loss was on average $63 \mathrm{ml}$, and 5 of 6 patients required an intraoperative transfusion of blood products.

The mean extent of immediate calvarial vault volume reduction was $44.5 \%( \pm 3.9 \%)$. The mean cranial volume at 1 month was $67.4 \%$ of the preoperative volume, and the mean cranial volume was $101.7 \%$ of the preoperative volume at last radiographic follow-up, which was on average at 46.2 months after surgery (Table 2). In 2 of 5 patients with follow-up, cranial volumes had not reached the original preoperative volume at greater than 5 years after surgery.

In the first patient to undergo VPS placement + CVRF, an excellent cranial volume reduction was achieved following CVRF, but the patient was discovered to have multifocal intraparenchymal hemorrhages approximately 1 week following this procedure. The family chose to withdraw care because of the overall poor prognosis associated with holoprosencephaly, which could have been exacerbated by the intracranial hemorrhages. No other patient treated with VPS placement + CVRF suffered a postoperative intraparenchymal hemorrhage or any other hemorrhagic or neurological complication.

In the follow-up period, one patient (patient 3) treated with VPS placement + CVRF required placement of a subduroperitoneal shunt in addition to the original VPS, and another (patient 5) required endoscopic fenestration of an intracranial cyst. Patient 3 also required shunt externalization and reinternalization due to bladder rupture 
TABLE 1. Characteristics of patients with severe hydrocephalic macrocrania

\begin{tabular}{|c|c|c|c|c|c|c|c|c|c|c|c|c|}
\hline \multirow[b]{2}{*}{ Pt No. } & \multirow[b]{2}{*}{$\begin{array}{l}\text { Etiology } \\
\text { of } \mathrm{HCP}\end{array}$} & \multirow[b]{2}{*}{ Type of CVRF } & \multirow[b]{2}{*}{$\begin{array}{l}\text { Day of } \\
\text { Shunt }^{*}\end{array}$} & \multirow[b]{2}{*}{$\begin{array}{l}\text { Valve } \\
\text { Type }\end{array}$} & \multirow[b]{2}{*}{$\begin{array}{l}\text { Day of } \\
\text { CVRF* }^{*}\end{array}$} & \multirow[b]{2}{*}{$\begin{array}{c}\text { Preop } \\
\text { OFC (cm) }\end{array}$} & \multicolumn{2}{|c|}{ Cranial Vol $\left(\mathrm{cm}^{3}\right)$} & \multirow[b]{2}{*}{$\begin{array}{c}\text { Cranial } \\
\text { Reduction (\%) }\end{array}$} & \multirow{2}{*}{$\begin{array}{l}\mathrm{EBL} \\
(\mathrm{ml})\end{array}$} & \multirow{2}{*}{$\begin{array}{c}\text { Op } \\
\text { Duration } \\
\text { (mins) }\end{array}$} & \multirow[b]{2}{*}{$\begin{array}{l}\text { PRBCs } \\
(\mathrm{ml})\end{array}$} \\
\hline & & & & & & & Preop & Postop & & & & \\
\hline \multicolumn{13}{|l|}{ VPS + CVRF } \\
\hline 1 & $\mathrm{HP}$ & Anterior & 3 & Pro & 5 & 49 & 1629.3 & 829.1 & 49.1 & 15 & 87 & 0 \\
\hline 2 & AS & Anterior & 2 & Pro & 3 & 50 & 1842.1 & 982.8 & 46.6 & 20 & 45 & 28 \\
\hline 3 & AS & Anterior† & 4 & Pro & 7 & 50 & 1732.5 & 900.1 & 48.0 & 10 & 109 & 60 \\
\hline 4 & $\mathrm{HP}$ & Anterior & 0 & Pro & $45 \ddagger$ & 53 & 2233.0 & 1298.3 & 41.9 & 175 & 107 & 310 \\
\hline 5 & DW & Anterior + posterior & 1 & Pro & 1 & 54 & 1842.3 & 1070.2 & 41.9 & 60 & NA & 60 \\
\hline 6 & HP & Anterior + posterior & 18 & Pro & $37 \ddagger$ & 60 & 1521.0 & 918.9 & 39.6 & 100 & 191 & 180 \\
\hline \multicolumn{13}{|c|}{ VPS only (no CVRF) } \\
\hline 7 & $\mathrm{HP}$ & None & 3 & MD & NA & 50 & 1475.5 & NA & NA & NA & NA & NA \\
\hline 8 & DW & None & 1 & MD & NA & 57 & 2262.5 & 1993.2 & 11.9 & NA & NA & NA \\
\hline 9 & AS & None & 1 & MD & NA & 49 & 1503.9 & NA & NA & NA & NA & NA \\
\hline 10 & AS & None & 3 & $M D$ & NA & 50 & 1645.5 & 1328.3 & 19.3 & NA & NA & NA \\
\hline 11 & AS & None & 3 & Pro & NA & 49 & 1548.2 & 1201.8 & 22.3 & NA & NA & NA \\
\hline
\end{tabular}

$\mathrm{AS}=$ aqueductal stenosis; $\mathrm{DW}=$ Dandy-Walker malformation; $\mathrm{EBL}$ = estimated blood loss; $\mathrm{HC}=$ head circumference; $\mathrm{HCP}=$ hydrocephalus; $\mathrm{HP}=$ holoprosencephaly; $\mathrm{MD}=$ medium pressure; $\mathrm{NA}=$ not applicable; $\mathrm{OFC}=$ orbitofrontal circumference; pro = programmable; $\mathrm{PRBC} s=$ transfusion with packed red blood cells; $\mathrm{pt}=$ patient .

* Indicates the day of life when the procedure was performed.

† Second-stage posterior cranial vault remodeling procedure performed 1 year later due to persistent turricephaly.

$\ddagger$ Delays of surgery in patient 4 due to referral after initial management with shunting alone and in patient 6 due to a large area of cutis aplasia surgically excised prior to CVR.

several weeks after surgery, which was not directly related to VPS insertion or to the CVRF. The mean number of shunt setting adjustments not related to MR after CVRF was $1.6( \pm 1.5)$.

At last follow-up, various craniometric measurements were obtained and are shown in Table 3. The mean head circumference at the latest follow-up was $52.6 \mathrm{~cm}$, and the mean head circumference percentile was $80 \%$ (range $50 \%-99 \%)$. The mean cranial index was $0.78( \pm 0.08)$. The mean ODD and ODDi were $8.4 \mathrm{~mm}( \pm 2.9 \mathrm{~mm})$ and $104.8 \%( \pm 2.0 \%)$, respectively.

Developmental data were collected using the ASQ-3 parent questionnaire, and 5 developmental domains were evaluated in 5 patients (Table 4). All of the children fell

TABLE 2. Cranial volume measurements in patients with extreme hydrocephalic macrocrania

\begin{tabular}{|c|c|c|c|c|c|}
\hline \multirow[b]{2}{*}{ Pt No. } & \multicolumn{4}{|c|}{ Cranial Vol in $\mathrm{cm}^{3}$ (\% preop) } & \multirow{2}{*}{$\begin{array}{l}\text { Age at Most Recen } \\
\text { Imaging (mos) }\end{array}$} \\
\hline & Preop & Postop* & 1 Mo Postop & Most Recent FU & \\
\hline \multicolumn{6}{|c|}{ VPS + CVRF } \\
\hline 1 & 1629.3 & $829.1(50.9)$ & NA & NA & NA \\
\hline 2 & 1842.1 & $982.8(53.4)$ & $1167.0(63.4)$ & $1923.6(104.4)$ & 69 \\
\hline 3 & 1732.5 & $900.1(52.0)$ & $1068.7(61.9)$ & $1590.0(91.8)$ & 63 \\
\hline 4 & 2233.0 & $1298.3(58.1)$ & $1607.6(72.0)$ & $2546.7(114.0)$ & 46 \\
\hline 5 & 1842.3 & $1070.2(58.1)$ & $1181.2(64.1)$ & $1967.2(106.8)$ & 36 \\
\hline 6 & 1521.0 & $918.9(60.4)$ & $1041.0(68.4)$ & $1121.7(73.7)$ & 17 \\
\hline Mean & 1800.0 & $1000.0(55.6)$ & $1213.1(66.0)$ & $1829.8(98.1)$ & 46.2 \\
\hline \multicolumn{6}{|l|}{ VPS only } \\
\hline 7 & 1475.5 & NA & NA & NA & NA \\
\hline 8 & 2262.5 & $1993.2(88.1)$ & NA & $2077.4(140.8)$ & 24 \\
\hline 9 & 1503.9 & NA & $973.7(64.7)$ & $1425.6(94.8)$ & 121 \\
\hline 10 & 1645.5 & $1328.3(80.7)$ & NA & NA & NA \\
\hline 11 & 1548.2 & $1201.8(77.6)$ & $1070.7(69.2)$ & $2230.4(144.1)$ & 65 \\
\hline Mean & 1687.1 & $1507.8(82.1)$ & $1022.2(67.0)$ & $1911.1(126.6)$ & 70 \\
\hline
\end{tabular}

$\mathrm{FU}=$ follow-up.

* Immediate postoperative volume following CVRF for VPS + CVRF group and following VPS insertion for VPS-only group. 
TABLE 3. Most recent follow-up data for patients born with extreme hydrocephalic macrocrania

\begin{tabular}{|c|c|c|c|c|c|c|c|c|c|c|}
\hline \multirow[b]{2}{*}{ Pt No. } & \multirow[b]{2}{*}{$\begin{array}{c}\text { FU } \\
\text { (mons) }\end{array}$} & \multirow[b]{2}{*}{$\begin{array}{l}\text { Cranial } \\
\text { Index }\end{array}$} & \multirow[b]{2}{*}{$\begin{array}{l}\mathrm{HC} \\
(\mathrm{cm})\end{array}$} & \multirow[b]{2}{*}{$\begin{array}{c}\mathrm{HC} \\
\text { Percentile }\end{array}$} & \multirow[b]{2}{*}{$\begin{array}{l}\text { ODD } \\
(\mathrm{mm})\end{array}$} & \multirow[b]{2}{*}{$\begin{array}{c}\text { ODDi } \\
(\%)\end{array}$} & \multicolumn{2}{|c|}{ Parental Satisfaction } & \multicolumn{2}{|c|}{ Surgical Team Satisfaction } \\
\hline & & & & & & & $\begin{array}{l}\text { Overall Esthetic } \\
\text { Satisfaction }\end{array}$ & $\begin{array}{l}\text { Satisfaction } \\
\text { Level (1-5) }\end{array}$ & $\begin{array}{l}\text { Overall Esthetic } \\
\text { Satisfaction }\end{array}$ & $\begin{array}{l}\text { Satisfaction } \\
\text { Level (1-5) }\end{array}$ \\
\hline \multicolumn{11}{|c|}{ VPS + CVRF } \\
\hline 1 & $0^{*}$ & Died & Died & Died & Died & Died & Died & Died & Died & Died \\
\hline 2 & 60 & 0.76 & 53 & 78 & 6 & 103 & Yes & 5.0 & Yes & 3.5 \\
\hline 3 & 53 & 0.80 & 52 & 83 & 5 & 103 & Yes & 5.0 & Yes & 3.7 \\
\hline 4 & 52 & 0.90 & 61 & 99 & 10 & 105 & Yes & 5.0 & Yes/no & $2.3 \dagger$ \\
\hline 5 & 40 & 0.78 & 52 & 92 & 9 & 105 & Yes & 5.0 & Yes & 3.7 \\
\hline 6 & 10 & 0.66 & 53 & 80 & 12 & 108 & No & 3.5 & No & 1.0 \\
\hline \multicolumn{11}{|l|}{ VPS only } \\
\hline 7 & $0^{*}$ & Died & Died & Died & Died & Died & Died & Died & Died & Died \\
\hline 8 & $0^{*}$ & Died & Died & Died & Died & Died & Died & Died & Died & Died \\
\hline 9 & 123 & NA & 52 & 27 & NA & NA & No & 2.0 & No & 2.0 \\
\hline 10 & 115 & 1.00 & 53 & 75 & 12 & 107 & Yes & 4.0 & No & 3.0 \\
\hline 11 & 68 & 0.68 & 57 & 99 & 30 & 112 & Yes & 4.0 & Yes & 3.5 \\
\hline
\end{tabular}

* Died during initial hospitalization or before follow-up.

$\dagger$ Patient referred from outside institution and underwent CVRF at 45 days.

near to below age expectations for gross motor and fine motor skills. Three of 5 fell near to below age expectations for communication, and 4 of 5 fell near to below age expectations for personal-social skills. Problem-solving skills were strongest in all except 1 patient, with 2 of 5 falling near to below age expectations.

Photographs taken at each patient's most recent followup are shown in Fig. 3. Families were asked to rate their level of esthetic satisfaction with the CVRF procedure: 4 $(80 \%)$ of 5 families reported "yes," while 1 family reported "no." When given a scale regarding level of esthetic satisfaction ( $1=$ unsatisfied; $5=$ very satisfied; $2-4=$ in between), 4 (80\%) of 5 families reported 5 , while 1 family reported 3.5. When families were asked whether they were glad they underwent this operation, 5 out of 5 re- ported "yes." A similar evaluation scale for esthetic outcomes was given to 4 members of the clinical and research teams. Across all 5 patients, the mean esthetic score was $2.8( \pm 1.2)$.

\section{VPS-Only Outcomes}

Extended clinical follow-up for the group of 5 patients who underwent VPS alone was available for 3 patients with a median follow-up of 115 months (range 68-123 months). Two of 5 patients died in the follow-up period: one underwent hospice care early in life, and the other died at the age of 3 years due to complications related to a pulmonary infection. Both patients who died had grossly misshapen heads, but photographic documentation was not available.

TABLE 4. Developmental testing of patients with extreme hydrocephalic macrocrania

\begin{tabular}{|c|c|c|c|c|c|c|}
\hline \multirow[b]{2}{*}{ Pt No. } & \multicolumn{5}{|c|}{ ASQ Domains } & \multirow[b]{2}{*}{$\%$ Below Cutoff } \\
\hline & Communication & Gross Motor & Fine Motor & Problem Solving/Conceptual & Personal-Social & \\
\hline \multicolumn{7}{|c|}{ VPS + CVRF } \\
\hline 1 & Died & Died & Died & Died & Died & Died \\
\hline 2 & Above & Below & Near & Above & Near & $20 \%$ \\
\hline 3 & Below & Below & Below & Above & Below & $80 \%$ \\
\hline 4 & Below & Below & Below & Near & Below & $80 \%$ \\
\hline 5 & Above & Below & Near & Above & Above & $20 \%$ \\
\hline 6 & Below & Below & Near & Below & Below & $80 \%$ \\
\hline \multicolumn{7}{|l|}{ VPS only } \\
\hline 7 & Died & Died & Died & Died & Died & Died \\
\hline 8 & Died & Died & Died & Died & Died & Died \\
\hline 9 & NA & NA & NA & NA & NA & NA \\
\hline 10 & Below & Below & Below & Below & Below & $100 \%$ \\
\hline 11 & Below & Below & Below & Below & Below & $100 \%$ \\
\hline
\end{tabular}



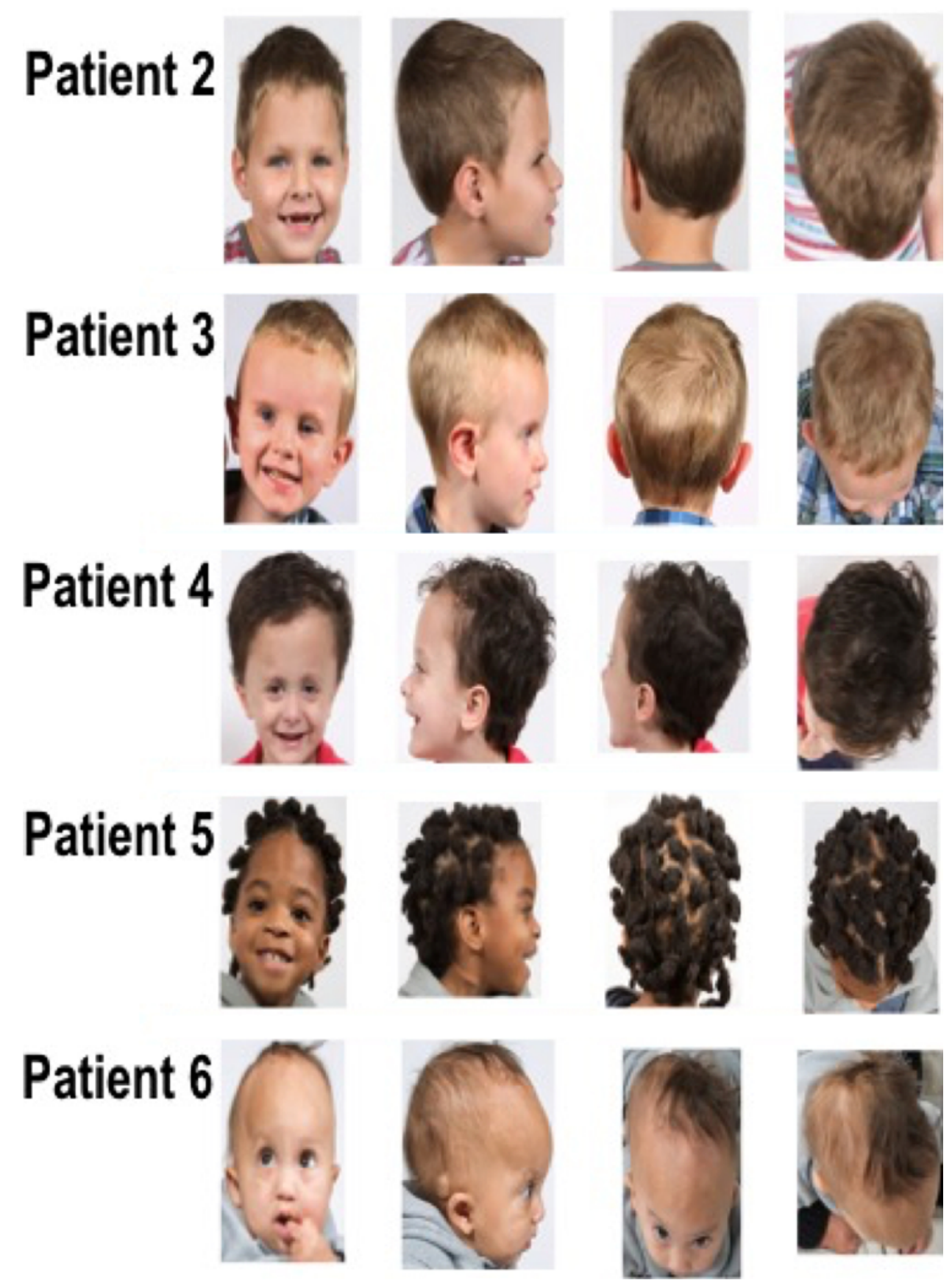

FIG. 3. Follow-up photographic data showing esthetic outcomes for 5 patients with extreme hydrocephalic macrocephaly who underwent shunting and CVRF. Patient 1 is not listed due to death during initial hospitalization. Patient 4 was referred after VPS with significant deformity, undergoing CVRF later (45 days) than other patients in this group. Figure is available in color online only.

Four patients who underwent VPS alone had placement of a medium-pressure valve, and the remaining patient underwent implantation of a programmable VPS. Two of the 4 patients with at least 6 months of follow-up required no shunt revisions in the 1st year of life, while one patient underwent 4 revisions and another required 8 revisions.

Cranial volumetric analysis demonstrated a mean preoperative cranial volume of $1687.1 \mathrm{~cm}^{3}$. Following shunt placement, the mean immediate cranial volume reduction was $17.9 \%$. One month after VPS placement, the mean cra- nial volume was $67 \%$ of the preoperative volume, and at latest radiographic follow-up, at a mean 70 months of age, the mean cranial volume was $126.6 \%$ of the preoperative volume.

During the follow-up period, one of the surviving patients had difficult-to-manage hydrocephalus, even with the placement of a programmable shunt and multiple adjustments, because of a pseudomeningocele with underdrainage and a misshapen head with overdrainage. Multiple shunt revisions were required, and at one point the shunt 


\section{Patient 8}
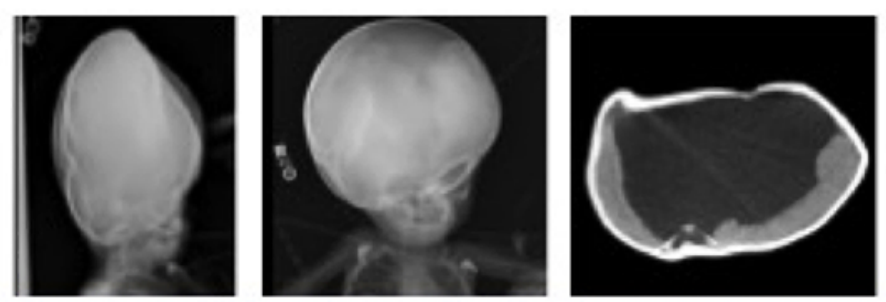

\section{Patient 9}
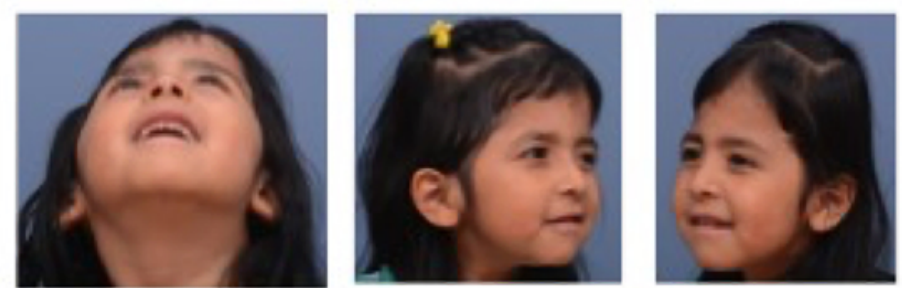

\section{Patient 10}
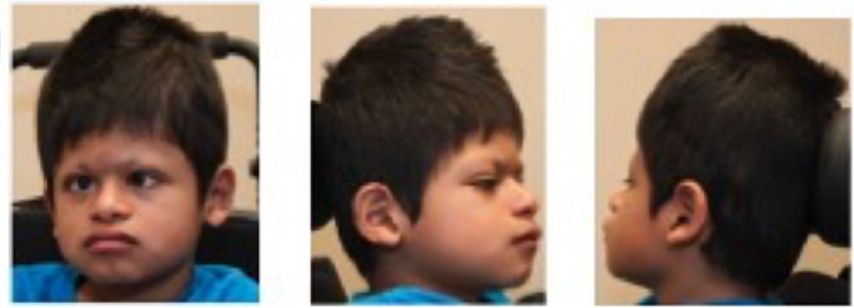

\section{Patient 11}
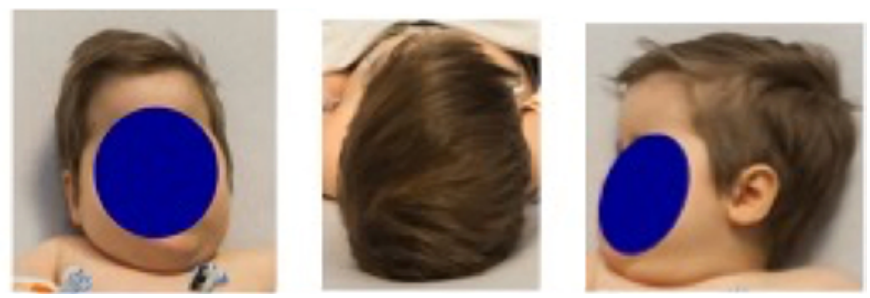

FIG. 4. Imaging and esthetic outcomes in patients with extreme hydrocephalic macrocephaly following shunting and no CVRF. In patient 8 , plain radiographs demonstrate hydrocephalic macrocephaly and cranial deformity following VSP insertion. Follow-up photographs for patients 9-11 are shown. Patient 10 underwent multiple open cranial vault reconstructions following these images. Figure is available in color online only.

was found to be infected; it required removal and temporary external ventricular drainage. Another patient underwent 2 separate open cranial vault reconstruction procedures to treat significant cranial deformity later in life. The mean follow-up head circumference was $54 \mathrm{~cm}( \pm 2.6 \mathrm{~cm})$ with a variable head circumference percentile of $44.3 \%$ ( \pm 48.4\%).

Developmental data for patients with extended followup demonstrated developmental scores below the cutoff in all categories for all patients. Photographs and radiographs taken at the most recent follow-up (if available) are presented in Fig. 4. The mean parental esthetic satisfaction score was 3.3. The mean clinical and research team esthetic evaluation score was 2.8 .

\section{Discussion}

\section{History of Calvarial Vault Reconstruction for Extreme} Macrocephaly

A variety of surgical techniques have been described to reduce calvarial volumes in an effort to decrease morbidity associated with severe hydrocephalic macrocephaly. $6,7,10,11,14,18$ Overdrainage due to ventricular shunting can result in dramatic cranial vault collapse, which leads to overriding sutures, potentially leading to the unwanted clinical scenario of secondary craniosynostosis that results in a severely misshapen head. ${ }^{1,5,12,13}$ Fortunately, this situation is rare, but when it occurs, it poses a significant challenge for clinicians and families alike due to problems with patient positioning, difficulties in hydrocephalus management, and poor esthetic results.

Historically, craniofacial reconstruction for hydrocephalic macrocephaly has been performed in patients older than 6-12 months of age, many times being deferred to later in childhood or adolescence. These delayed reduction cranioplasties are technically challenging, sometimes performed in multiple stages, and are high-risk procedures given the prolonged anesthetic time and extensive intracranial and shunt exposure, which can lead to large blood volume loss, coagulopathy, infection, and even death., ${ }^{2,914,19}$ 


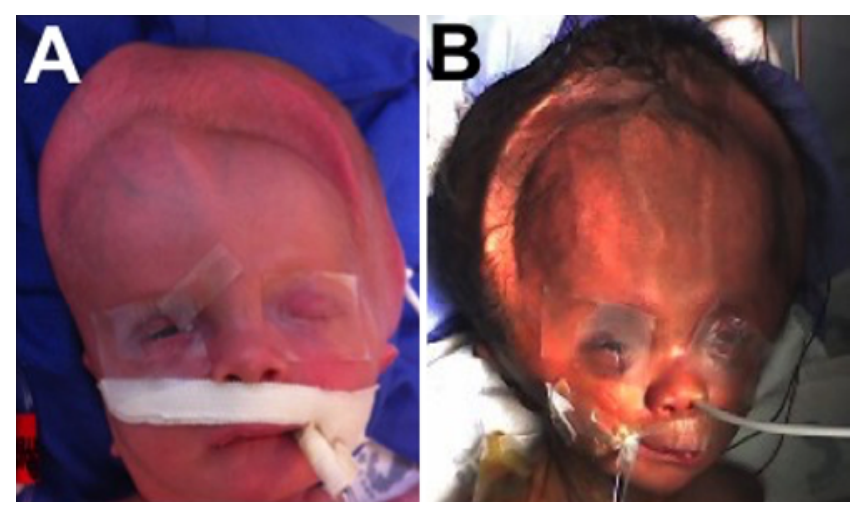

FIG. 5. Cranial disfigurement postshunting in patients with extreme macrocephaly due to hydrocephalus. A and B: Photographs demonstrating severe deformity and overlap associated with the frontal and parietal bones following ventricular shunting placement in 2 patients with severe hydrocephalic macrocrania. Figure is available in color online only.

\section{Rationale and Evolution of the CVRF Technique in Neonates}

In this study, we describe our experience with patients born with extreme macrocephaly related to hydrocephalus managed in the neonatal period with either VPS placement alone or VPS placement + CVRF (Fig. 1).

We chose to use CVRF after struggling for many years with the management of newborns with such extreme forms of craniocerebral disproportion. Decades of experience with CSF shunting, endoscopic third ventriculostomy, and endoscopic third ventriculostomy + choroid plexus cauterization in such patients led to difficulties in CSF diversionary management as well as esthetic and positioning difficulties. For example, overdrainage was associated with subdural hematomas and hygromas, frequent shunt revisions and reprogramming, and grotesque overlapping of disproportionately large cranial bones, resulting in severe deformities and even premature craniosynostosis (Fig. 5). Families were often fearful of moving these infants due to their mobile and grossly overlapped cranial bones.

Among the patients we report here, $40 \%$ of those with extreme hydrocephalic macrocephaly in whom a VPS placement alone was performed died during the follow-up period, evidence of the poor prognosis associated with this condition. Finding the perfect balance between under- and overdrainage has proved elusive for us in the majority of our neonatal patients with massive craniomegaly related to extreme hydrocephalus prior to the implementation of CVRF at our institution.

Even with our best efforts to minimize these deformities through repositioning, shunt reprogramming, or cranial orthotic use, some of the surviving patients who had been treated with VPS only were left with permanent, disfigured head shapes and morbidity in the form of multiple shunt revisions and infection due to difficult-to-manage CSF dynamics. The 2 VPS-only patients who died had grotesquely misshapen heads. Of the remaining 3 patients, 2 had acceptable esthetic outcomes, but 1 had a severe enough deformity that she and her family requested anterior and posterior calvarial vault remodeling (patient 9).
Patients in the VPS-only group also had greater difficulty with their shunt management, requiring more revisions than patients who underwent VPS placement + CVRF. One surviving patient who underwent VPS placement alone required 8 shunt revisions for infection and a pseudomeningocele in the 1st year of life, even with use of a programmable shunt valve. It is possible that some of the esthetic and CSF-related management difficulties encountered in the VPS-only group could be related to the use of fixed-pressure CSF valves, but we also faced significant shunt-related problems in the patient who did have a programmable valve in this group. These difficulties motivated us to develop the CVRF technique to facilitate patient care and improve long-term esthetic outcomes.

The result documented in our first patient, who underwent VPS placement + CVRF and in whom multiple intracranial hemorrhages were discovered a week after CSF shunting and CVRF, was discouraging. However, we carried on because the immediate esthetic result was excellent, there was an increased ease with which the head could be manipulated to care for the child, and we could not definitively correlate the hemorrhages to the CVRF procedure. This patient had multiple medical issues and very abnormal cerebral architecture with minimal cortical tissue. His parents were inclined to consider early termination of treatment even prior to CVRF because of the their child's poor overall prognosis.

Our experience with the other 5 patients who underwent VPS placement + CVRF (patients 2-6) was instructive. Compared with the VPS-only patients, we found that the additional fixation of the bones with CVRF allowed us to more easily treat CSF drainage without causing cranial bone overlap and cranial deformity. The families and other health care providers found that positioning and overall care were facilitated by the rigid fixation of the previously mobile cranial bones.

All 5 patients available for follow-up tolerated the CVRF procedure well, with no intraoperative instability or significant surgical complication. Three patients (patients 2-4) underwent fixation of their anterior skull alone, with head size reduction occurring as a result of approximating the frontal and parietal bones at the anterior fontanel. These 3 operations involved minimal blood loss, the patients had no complications directly referable to the CVRF procedure, they recovered well, and they had a good esthetic outcome when viewed from the front. However, they all had an element of posterior turricephaly, the result of the persistent prominence of large posterior parietal bones relative to the well-approximated anterior frontal and parietal bones (Fig. 6). The family of one of these patients (patient 3) subsequently elected to have us perform a posterior CVRF when their child was 1 year of age to address this deformity, but the other families thought that the posterior skull deformity was not severe enough to justify further intervention. Photographs clearly show the posterior prominence of the parietal bone in patient 2 , who did not undergo posterior remodeling, compared with patient 3, who did (Fig. 3).

To address the issue of posterior parietal turricephaly after anterior CVRF, the most recently treated 2 patients underwent a more extensive operation to fixate the parietal 


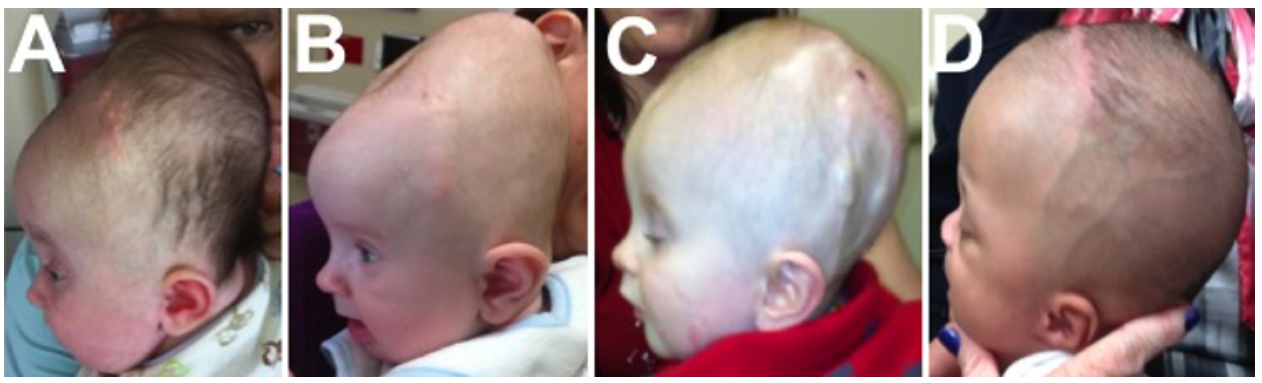

FIG. 6. Posterior turricephaly following anterior CVRF. A: Patient 4 with posterior turricephaly after anterior CVRF. No further cranial vault surgery was performed, and improvement was demonstrated over time (see Fig. 3). B: Patient 3 with severe posterior turricephaly a few months after anterior CVRF. C: Patient 3 approximately 6 months after secondary CVR, performed 1 year after anterior CVRF. D: Patient 5 approximately 6 months after simultaneous anterior and posterior CVRF. Figure is available in color online only.

bones to both the frontal bones and the occipital bone. As expected, the combined anterior-posterior procedure resulted in greater operating time and more blood loss, but our results were good in the first patient in whom it was performed (patient 5). By fixating both the front and back of the head, while also trimming a crescent-shaped portion of the posterosuperior parietal bone, the esthetic result was improved. The rigid fixation of the back of the head also produced a more stable posterior construct than would be achieved by the anterior-only approach, which facilitated the child's care.

Emboldened by the results of a combined anterior and posterior CVRF in patient 5, we pushed the limits of the technique in patient 6 , and the result was a poor cosmetic outcome. Unlike the previous patients, patient 6 was born with a large area of posterior cutis aplasia, which was resected at 3 weeks of age, after the VPS was placed. Because we thought CVRF could possibly be complicated by the resection of the scalp abnormality, our intent was to try to avoid CVRF by performing multiple shunt valve adjustments. Despite numerous valve reprogrammings and vigilant attempts at repositioning, the patient's head was grossly deformed within the 1st month of life. We then chose to perform a CVRF, utilizing incisions that incorporated the previous scalp incision for cutis aplasia resection. In addition, we chose to perform barrel-stave osteotomies on the posterior parietal bone rather than resecting a crescent-shaped piece of the protuberant posterior parietal bone. This maneuver, combined with the technical difficulties associated with the use of prior incisions, led to an unstable construct that allowed the bones to shift over time, which resulted in an abnormal head shape similar to the appearance of a child with severe positional plagiocephaly (parallelogram shape). In retrospect, an initial anterior-only CVRF with possible staging of a second posterior CVRF would have been prudent in this particular patient. The parents and our surgical team consider this child's outcome poor, and we anticipate performing revision cranial surgery in the future.

\section{Benefits and Limitations of the Technique}

Although our experience shows that there are certainly risks and limitations associated with the CVRF technique, we believe that this procedure can play a beneficial role in the management of extreme forms of neonatal hydrocephalic macrocrania in a small subset of patients. Overall, CVRF for neonates with severe hydrocephalic macrocephaly simplified shunt management, eased the burdens on parents of repositioning their child, and led to improved esthetic and clinical results.

Learning from our experience with neonates with severe hydrocephalic macrocephaly, we expect that future patients with this disorder will undergo early shunt placement with a programmable valve at our hospital. If significant issues arise with CSF dynamics (over- or underdrainage) or if severe, disfiguring overlapping sutures develop despite valve adjustment and patient repositioning, we plan to first perform an anterior CVRF in an attempt to overcome these issues. If, despite undergoing anterior CVRF, significant posterior turricephaly were to occur, we would consider a separately staged posterior CVRF procedure with removal of a crescent-shaped piece of oxycephalic posterior parietal bone along with fixation. Further technical refinement, greater experience with the technique, and a better understanding of ideal patient selection and surgical timing may lead to better outcomes.

Overall, in our cohort of patients who underwent shunting alone, 3 of 5 had a poor esthetic outcome, compared with 1 patient who underwent VPS placement + CVRF. Of these 3 VPS-only patients with a poor esthetic outcome, 2 died and 1 required an extensive cranial vault remodeling procedure later in life. In addition, patients who underwent VPS placement + CVRF had better overall developmental outcomes than those who underwent VPS alone. While this is certainly not a conclusive finding based on our small cohort, it is possible that the CVRF procedure allows infants to more normally develop based on these initial evaluations. Given the overall findings, the safety and effectiveness of the CVRF technique appear promising in this subset of patients with extreme hydrocephalic macrocephaly. However, future studies and a multiinstitutional experience will help to further define the best indications for this technique.

\section{Conclusions}

Neonatal CVRF may have a beneficial role in a subset of young infants with extreme macrocrania $(>49 \mathrm{~cm})$ 
secondary to severe hydrocephalus who develop disfiguring head shapes after CSF diversion due to overlapping of disproportionately large cranial bones.

\section{Acknowledgments}

We are indebted and thankful to the patient families for their trust in us, for allowing us to manage their children's hydrocephalus, and for returning for frequent and thorough follow-up visits during this study. Allyn DeVito dedicated countless hours to the composition of suitable photographs. Peter A. DiPaolo, LPO, CPO, from Hanger Orthotics, measured the cranial head shapes. Michelle Haers, RN, provided technical assistance and humored her surgeons as they developed this technique. Sharon Ghazarian, $\mathrm{PhD}$, performed extensive hospital medical record inquiries to help us identify patients for this study. Peter Elfert assisted with calvarial volume analysis. Luis Rodriguez, MD, and Bruce Storrs, $\mathrm{MD}$, also contributed their patients in the VPS-only group, and they helped us manage patients in the VPS placement + CVRF group. Devon Truong, PAC, who co-invented this procedure with the corresponding author, was an enthusiastic, creative, and meticulous partner before his tragic, premature death in 2014.

\section{References}

1. Doorenbosch X, Molloy CJ, David DJ, Santoreneos S, Anderson PJ: Management of cranial deformity following ventricular shunting. Childs Nerv Syst 25:871-874, 2009

2. Dorafshar A, Fisher M, Borsuk D, Fishman E, Ahn E: A novel application of computer-aided design and manufacturing for reduction cranioplasty. J Craniofac Surg 25:172-176, 2014

3. Drotar D, Stancin T, Dworkin PH, Sices L, Wood S: Selecting developmental surveillance and screening tools. Pediatr Rev 29:e52-e58, 2008

4. Ehni G: Reduction of head size in advanced hydrocephalus: a case report. Neurosurgery 11:223-228, 1982

5. Faulhauer K, Schmitz P: Overdrainage phenomena in shunt treated hydrocephalus. Acta Neurochir (Wien) 45:89-101, 1978

6. Gage EA, Price AV, Swift DM, Sacco DJ, Fearon JA: Limited reduction cranioplasty for the treatment of hydrocephalic macrocephaly. Plast Reconstr Surg 128:1272-1280, 2011

7. Kohan E, Jackson E, Heller J, Lazareff J, Bradley JP: Correction of hydrocephalic macrocephaly with total cranial vault remodeling and molding helmet therapy. Plast Reconstr Surg 125:1763-1770, 2010

8. Manwaring JC, Truong D, Deukmedjian AR, Carey CM, Storrs BB, Rodriguez LF, et al: Cranial reduction and fixation with a resorbable plate combined with cerebrospinal fluid shunting for difficult-to-manage macrocephaly related to hydrocephalus. J Neurosurg Pediatr 11:210-213, 2013

9. Mathews MS, Loudon WG, Muhonen MG, Sundine MJ: Vault reduction cranioplasty for extreme hydrocephalic macrocephaly. J Neurosurg 107 (4 Suppl):330-337, 2007
10. Park TS, Grady MS, Persing JA, Delashaw JB: One-stage reduction cranioplasty for macrocephaly associated with advanced hydrocephalus. Neurosurgery 17:506-509, 1985

11. Piatt JH Jr, Arguelles JH: Reduction cranioplasty for craniocerebral disproportion in infancy: indications and technique. Pediatr Neurosurg 16:265-270, 1990-1991

12. Schendel SA, Shuer LM: Multiple-suture synostosis subsequent to ventricular shunting. Plast Reconstr Surg 93:10731077, 1994

13. Shuster BA, Norbash AM, Schendel SA: Correction of scaphocephaly secondary to ventricular shunting procedures. Plast Reconstr Surg 96:1012-1019, 1995

14. Sundine MJ, Wirth GA, Brenner KA, Loudon WG, Muhonen MG, Greene CS, et al: Cranial vault reduction cranioplasty in children with hydrocephalic macrocephaly. J Craniofac Surg 17:645-655, 2006 (Erratum in J Craniofac Surg 27:274, 2016)

15. Valla L, Wentzel-Larsen T, Hofoss D, Slinning K: Prevalence of suspected developmental delays in early infancy: results from a regional population-based longitudinal study. BMC Pediatr 15:215, 2015

16. van Wijk RM, van Vlimmeren LA, Groothuis-Oudshoorn CG, Van der Ploeg CP, IJzerman MJ, Boere-Boonekamp MM: Helmet therapy in infants with positional skull deformation: randomised controlled trial. BMJ 348:g2741, 2014

17. Ventureyra EC, Da Silva VF: Reduction cranioplasty for neglected hydrocephalus. Surg Neurol 15:236-238, 1981

18. Vries JK, Habal MB: Cranio-orbital correction for massive enlargement of the cranial vault. Plast Reconstr Surg 63:466-472, 1979

19. Winston KR, Ogilvy CS, McGrail K: Reduction cranioplasty. Pediatr Neurosurg 22:228-234, 1995

\section{Disclosures}

The authors report no conflict of interest concerning the materials or methods used in this study or the findings specified in this paper.

\section{Author Contributions}

Conception and design: Tuite. Acquisition of data: Tuite, Iyer, Carey, Rottgers, Tetreault, Shimony, Ruas. Analysis and interpretation of data: Tuite, Iyer, Katzenstein. Drafting the article: Tuite, Iyer. Critically revising the article: Tuite, Iyer, Carey, Rottgers, Shimony, Katzenstein. Reviewed submitted version of manuscript: all authors. Approved the final version of the manuscript on behalf of all authors: Tuite. Administrative/technical/material support: Tetreault. Study supervision: Tuite.

\section{Correspondence}

Gerald F. Tuite: Johns Hopkins All Children's Hospital, St. Petersburg, FL.gtuite1@jhmi.edu. 